\title{
Concentrated Solar Power technologies in Egypt, Morocco, and Italy, and their types
}

\author{
Ahmed Abdelkhalek Hashim \\ Sharkya STEM School \\ Giza, Egypt \\ ahmed.1419004@stemsharkya.moe.edu.eg \\ Abdelrahman Alaa Mohammed \\ Sharkya STEM School \\ Zagazig, Sharqia, Egypt \\ abd_elrahman.2219027@stemsharkya.moe.edu.eg \\ DOI: $10.31364 / \mathrm{SCIRJ} / \mathrm{V} 9.108 .2021 . P 0821873$ \\ http://dx.doi.org/10.31364/SCIRJ/v9.i08.2021.P0821873
}

\begin{abstract}
This research paper explains the importance of solar energy and the development of using concentrated solar power systems in some countries and their types. Solar power has been an exciting source of energy for many decades and is one of the most efficient energy sources of renewable sources. the IEA expected that world energy consumption will increase by 70$100 \%$ before 2050 . Many scientists wrote research papers about solar power and how it can be used in the north of Africa countries like Egypt and Morocco. The development of solar energy systems in the middle east and north Africa (MENA) has been taking new steps to the future with many devices and solutions to Harness solar power. This research paper, that showed the technologies of CSP which have been under developing and studying in the whole world especially the (MENA) countries like Morocco and Egypt. There will be also research papers that have shown that one of these technologies SPT can change the energy in the world forever. In this research paper, the idea and work mechanism of the (SPT) will be shown and explained and how did the studies explain that the (MENA) is the best area in the world to start this project that depends on the comparison between Italy and Egypt and the expectation of the results of using this device. The (SPT) device already has been proved in Morocco and it is now understudying in Egypt. As a conclusion, we figured that the (SPT) is the best (CSP) system to apply in Egypt as its efficiency is higher than the other types and Egypt can afford the place of constructing this device.
\end{abstract}

Index Terms - solar power, SPT, CSP, Egypt, Morocco (keywords)

\section{INTRODUCTION}

In the last few years, scientists have started to notice that fossil fuel won't be able to last for a long time and there must be another energy source before that happen. so, the alternative energy had a good effect on the scientists to study it and select the best of them to apply them worldwide. Solar power has been understudying in the whole world and has been developing by inventing a new technology that allows us to use solar power more efficiently. The studies showed that the best place to start developing solar technology was the (MENA) countries. All prior research about solar power and how to make the most benefit of it has approved that solar power is one of the most useable energy sources among alternative energies. The purpose of this research paper is to explain the importance of solar power as an energy source in the world and the development of its uses, technology, and devices. Also, the research paper will contain the analyses of the solution or the device that the selected research papers talked about which is the solar power generator and its four forms especially the (SPT) form, and how does work.

Of course, all the (MENA) countries are suitable for (CSP) systems but, studies showed that some countries can have more efficient results than others. For example, some comparisons have been done between Egypt and Morocco on the climate and temperature side. Moreover, it is interesting that some calculations showed that the average temperature in Egypt is higher than in Morocco. However, it is not that big difference but still working with a higher temperature means speeding up the process in the (CSP) system. In Morocco, it was recommended to use the (CSP) technology and until now it showed a huge step up economically and environmentally as it saves about 240000 tons of CO2 per year and about 0.5 USD per kilowatt which can be a great point considering applying such technology in Egypt.

Furthermore, talking about the expected aid from the (CSP) tech towards Egypt's economy, a list of numbers can be made. To begin with, the cost of applying a solar power tower in Egypt is nearly 1.2 billion dollars per project which is not that expensive considering the amount of savings from this project in the long term. Also, 0.003 USD will be saved per kilowatt using (SPT) technology which can make a huge difference in the economical side of the problem

\section{LITERATURE REVIEW AND THEORETICAL ANALYSIS}

Solar energy can be exploited in two main ways to generate power: direct conversion into electric energy using photovoltaic panels and using a thermodynamic cycle. Moreover, according to assessments of the International Energy Agency (IEA), the current world energy consumption will increase by $70-100 \%$ before 2050 which was a strength for the paper, (Patlitzianas, 2011). In Egypt, the studies of using solar thermal energy have reached high levels as they explained that Egypt belongs to the global sunbelt which is an advantage. Also, Egypt can be considered as an interesting example to show the practical possibilities of the development of Solar Energy in Southern Mediterranean countries. In Egypt, the population is almost concentrated in the delta and near Suez Canal and occupies only $6 \%$ of the land, with the remaining $94 \%$ of land as desert. The pattern of energy consumption by end-use in Egypt was $47 \%$ for Industry so Egypt must find new ways to save energy which was a weakness for the paper as it 
showed weaknesses in Egypt without solutions. According to research talked about Italy and Egypt in generating the solar power to see the advantages and use it for both countries, (CSP) facility installed in the south of Italy was then compared with one installed in Egypt and they found that The specific investment cost for (CSP) located in Gela, $12,775 € / \mathrm{kW}$, is $63 \%$ higher than the specific investment of the Egyptian installation, $7844 € / \mathrm{kW}$ which was strength point for the paper, (Desideri \& Campana, 2014). Another research paper talked about solar power and (CSP) in Morocco which is like Egypt's economic situation and location. It showed that Morocco hosts the largest (CSP) using parabolic trough collectors (PTC) as a technology for converting solar irradiation into thermal energy for electricity

generation, (Bouhal, et al., 2018). The research paper also expected that in 2030, 52\% of the installed capacity for electricity production is from renewable energies so

Egypt must reconsider using the (CSP) system.

After we studied factories that can make Egypt use (CSP) technology and weather conditions and knew benefits related to Morocco, we must understand how (CSP) technologies work, their types as in figure (1),

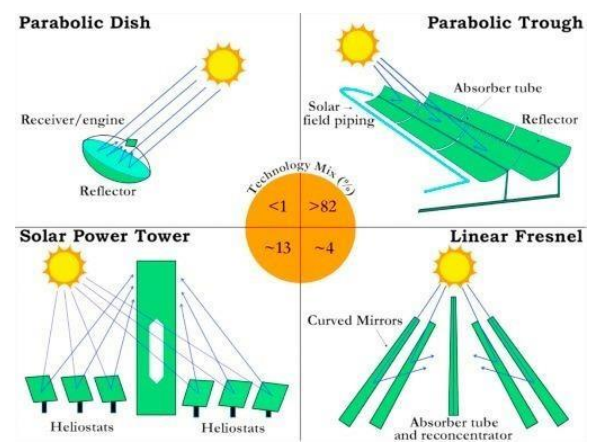

and what's the best

figure (1): types of the (CSP) technologies type for Egypt. One

meta-analysis study estimated the life cycle GHG emissions from the parabolic trough (CSP) after harmonization to be $69 \mathrm{~g}$ $\mathrm{CO} 2$ equivalent per $\mathrm{kWh}$ and for power tower CSP to be $25 \mathrm{~g}$ $\mathrm{CO} 2$ equivalent per $\mathrm{kWh}$ which was strength point for the paper (Rajavi, 2013)

Current (CSP) technologies cost around \$0.10 - \$0.12 per $\mathrm{kWh}$ of solar power. Department of Energy has established the SunShot Initiative which sets a cost goal of $\$ 0.06$ per $\mathrm{kWh}$ by 2020 . Technological improvements and financial incentives are expected to allow concentrated solar power to reach this goal.

(CSP) devices require water for cooling (like nuclear reactors). The amount of water consumption can be a concern given the arid nature of environments that are suitable for this technology. (CSP) water requirements are relatively high at about 3 liters per $\mathrm{kWh}$ compared to about 2 liters per $\mathrm{kWh}$ and 0.8 liters per $\mathrm{kWh}$ for coal and combined-cycle natural gas plants respectively. Dry cooling is an effective alternative as proven by the plants under construction in North Africa. Instead, Dry cooling can be used however at the cost of reduced production and increased cost. One study estimated that dry-cooling can reduce life-cycle water consumption by $77 \%$ while increasing GHG emissions by $8 \%$. The dry-cooling performance penalty of Power Towers can be smaller given their higher efficiency. The efficiency of the device changes from one country to another but it will be high in Egypt as Egypt is a sunbelt country (Rajavi, 2013)

\section{Types of (CSP) system \\ Linear Fresnel reflectors (LFR)}

(LFR) have a parabolic shape by using long rows of flat or slightly curved mirrors to reflect sun rays onto the downwardfacing linear receiver. The receiver is a fixed structure mounted over a tower above and along with the linear reflectors. In the daytime, the Fresnel reflectors are directed automatically toward the sun, and from there the reflected solar irradiation carries on to the linear tower where a receiver shaped like a long cylinder contains many tubes filled with water, (Islam, Huda, Abdullah, \& Saidur, 2018). With high solar radiation, the water evaporates and under pressure runs into a steam turbine that generates electricity. The main advantage of LFR systems is that their simple design of flexibly bent mirrors, fixed receivers require lower investment costs, facilitates the direct steam generation, thereby eliminating the need for heat transfer fluids and heat exchangers. This project doesn't cost much money but its weakness is that it has low efficiency compared with other (CSP) types.

\section{Parabolic Dish Systems (PDS)}

(PDS), concentrate sun rays at a focal point supported above the center of the dish. The concentrators are placed in an assembly with a two-axis tracking system that follows the sun. for efficient power conversion, Stirling/Brayton engine is placed with an electrical generator to utilize the concentrated heat on the receiver. At the focal point of this device, the temperature and pressure of the working fluid generally reach around $700-750{ }^{\circ} \mathrm{C}$ and 200 bar. We connected physics' (1.O) (9) to calculate the pressure of the focus point by using the $(\mathrm{P}=\Delta \mathrm{F} \div \Delta \mathrm{A})$ equation. Also, dishes are cooled by the surrounding air, so they don't require cooling water. Generally, the diameter of the SPD varies from 5 to $10 \mathrm{~m}$ and the surface area is $40-120 \mathrm{~m}^{2}$. Using these dishes, the reflectance of solar power can reach $90-94 \%$ which is an amazing percent in reflecting solar waves.

\section{Parabolic-trough collector (PTC)}

(PTC) the plant consists of a group of reflectors that are curved in one dimension in parabolic shape as in figure (2)

to focus sun rays onto an absorber tube that is mounted in the focal line of the parabola. The collector field comprises several hundred troughs that figure (2): the (PTC) device are placed in parallel rows

aligned on the north-south axis, (Zhang, Baeyens, Degrève, \& Cacères, 2013). This configuration enables single-axis troughs to track the sun from east to west throughout the day which means that the device works all daytime. Typically, thermal fluids are used as primary HTF such as oil, molten salts, etc. The temperature of the heated fluid can reach $400{ }^{\circ} \mathrm{C}$. As solar energy is concentrated $70-100$ times in the system, the operating temperature reaches $350-550{ }^{\circ} \mathrm{C}$. Solar-to-electric efficiency is $15 \%$ for the system of the (PTC). The first parabolic-trough system was developed in 1912 in Cairo, Egypt. At present, globally, there are 77 operational parabolic- 
trough power plants, and most of them are in Spain and the United States. And there is one in Egypt.

\section{Solar power tower (SPT)}

(SPT), use a heliostat field collector (HFC) which is thousands of heliostats arranged in a predetermined manner so that they reflect the maximum of the sunlight falling on them onto the central receiver atop the solar tower. Field of suntracking reflectors called heliostats that reflect and concentrate the sun rays onto a central receiver placed in the top of a tower. compensating for the sun's apparent motions in the sky. Heliostats are flat or slightly concave mirrors that follow the sun in two-axis tracking.

More energy from the sunlight strikes the earth in one hour than all the energy consumed by the human in the entire year. In the 1980s and 1990s, the United States demonstrated that SPT could collect and store heat to generate utility-scale electricity all day round, $24 \mathrm{~h}$ a day. In the central receiver, heat is absorbed by the heat transfer fluid (HTF), which then transfers heat to heat exchangers that power the steam Rankine power cycle. The concentrating power of the tower concept achieves very high temperatures, thereby increasing the efficiency at which heat is converted into electricity and reducing the cost of thermal storage, (Islam, Huda, Abdullah, $\&$ Saidur, 2018). The solar field consists of numerous computer-controlled mirrors that track the sun individually in two axes and reflect solar radiation onto the receiver located on the top of the tower. The receiver absorbs the heliostat reflected solar radiation and converts it into heat at hightemperature levels. Depending on the receiver design and heat transfer fluid nature, the upper working temperatures. The mechanisms of heliostats include losses due to cosine efficiency, blocking and shading, mirror reflectivity, tracking error, clean error, etc.

\section{The compounds of (SPT) solar tower}

The solar tower: Which is in the center of the solar thermal power plant houses the boiler drum. It receives radiation from heliostats and has some compounds.

\section{The receiver:}

In solar thermal collectors, a selective surface or selective absorber is a means of increasing its operating temperature and efficiency. Normally, a combination of materials is used. Recent researchers found that there are varieties of powdered and complementary powder, such as dye for paint count, that can be adjusted spectral selectivity by altering coating thickness, (Behar, Khellaf, \& Mohammedi, 2013). There was an attending in a research paper to explain the difference between all powders. They found that the infrared spectra of $\mathrm{CuCr} 0.5 \mathrm{Mn} 1.5 \mathrm{O} 4$ red shift compared with that of $\mathrm{CuCrMnO} 4$, considering the emittance distribution of the blackbody, (Geng, et al., 2012). The right coating can be selected according to the thermal emissions of the powder before coatings are made to obtain optimal spectral selectivity.

\section{Steam turbine:}

The steam turbine showed in figure (3) extracts thermal energy from pressurized steam and uses it to do mechanical work on rotating output

shaft and produce electricity and have another compound and until now, scientists still improve this technology. There were additional studies to know that there is an applied resultant force from the steam on the feathers of the turbine (Nag, 2015)

Water is impelled to receiver where concentrated solar radiation heats water to over $537^{\circ} \mathrm{C}$ and the boiling point of water is $100^{\circ} \mathrm{C}$. the fraction of the superhot steam is stored (in a heat storage tank) while the majority of the steam is sent to the power block for later use After that, high-pressure steam spins the turbine to produce electricity [8]. On the other hand, in an SPT where molten salt is used as working fluid, and travel in small pipes and if the pipes get small that will increase the speed of liquid and relatively cold molten salt at $290^{\circ} \mathrm{C}$ is pumped to the receiver where it is heated up to $565^{\circ} \mathrm{C}$, and then flows to the storage tank of hot molten salt like the specific heat $=1443+0.172 \mathrm{x}$ t $\mathrm{c}$. hot salt then flows through a heat exchanger from where heat is transferred to water, producing steam that spins a conventional Rankine-cycle turbine/generator system. The superheated steam enters into a high-pressure turbine. Then steam from the reheater section enters into a low-pressure turbine. Thereafter, steam coming out from the exhaust of the low-pressure turbine enters into a condenser where it is cooled and condensed into the water which is pumped back into the steam drum through the downcomer and to the bottom of the riser. high pressure and low-pressure turbines are coupled together to a generator that produces electricity and when the steam(pressure) acts on the specific place(volume) that makes kinetic energy and that make work (electricity). Here molten salt that has been cooled again is heated by the solar receiver and the process repeats itself continuously. in the book, there was a strength for explaining the whole idea of the turbine. Finally, molten salt then flows back to the cold storage tank. stored hot salt can produce steam and generate electricity efficiently for hours. saving may be of the order of $6 \%$ to $7 \%$ due to the

first $38^{\circ} \mathrm{C}$ of superheating and 4 to $5 \%$ for the next $38^{\circ} \mathrm{C}$ and so on.

\begin{tabular}{l|l|l|l|l|l} 
CSP & $\begin{array}{l}\text { Relative } \\
\text { Cost }\end{array}$ & $\begin{array}{l}\text { Land } \\
\text { Occupancy }\end{array}$ & $\begin{array}{l}\text { Thermo } \\
\text { dynamic } \\
\text { Efficiency }\end{array}$ & $\begin{array}{l}\text { Operating T } \\
\text { range }\left({ }^{\circ} \mathrm{C}\right)\end{array}$ & $\begin{array}{l}\text { Outlook for } \\
\text { Improvemen } \\
\text { ts }\end{array}$ \\
\hline PTC & Low & Large & Low & $20-400$ & Limited \\
\hline LFR & $\begin{array}{l}\text { Very } \\
\text { low }\end{array}$ & Medium & Low & $50-300$ & Significant \\
\hline SPT & High & Medium & High & $300-565$ & $\begin{array}{l}\text { Very } \\
\text { significant }\end{array}$ \\
\hline PDC & $\begin{array}{l}\text { Very } \\
\text { high }\end{array}$ & Small & High & $100-1000$ & $\begin{array}{l}\text { High } \\
\text { potential } \\
\text { through } \\
\text { mass } \\
\text { production }\end{array}$ \\
& \multicolumn{3}{|c|}{$\begin{array}{l}\text { Table (1): differences between CSP technologies } \\
\text { In }\end{array}$}
\end{tabular}

In table (1), We can know that the SPT device is the best CSP tech for Egypt.

\section{CONCLUSION}

We worked in our research to solve the problem in Egypt which is improving using renewable energy. We finished the research and found that Egypt is the best country in North Africa where thermal energy projects can be used with high efficiency because Egypt is characterized by high temperatures in the desert areas (red seacoast and the new valley). After searching for solutions., we found that SPT (solar power tower) is the best device that can be used in Egypt because of its high 
efficiency among the other (CSP) systems and it is appropriate to solve Egypt's energy problem (using arid areas). We knew that the (PTC) is the most common (CSP) device in the world although (SPT) has higher efficiency. It has the advantage of free input energy (solar energy). This project can operate an entire city, and when it is placed in the desert. Egypt will go to build new cities in the desert, and it will solve the problem of overpopulation and use the entire vast area of the country as a result of comparing with Morocco and appearing the similarity of the weather conditions and the economic status. Egypt must reconsider building this project in different desert areas as the device has been approved in another country and hired thousands of people and could power hundreds of houses. Also using this device will decrease the pollution in Egypt. This device has fulfilled all the requests that Egypt needs to produce energy from the sun to limit the use of fossil fuels and that this device is suitable for the environment and not contaminated with humans.

\section{RECOMMENDATION}

Investments are still at an experimental stage and haven't reached sufficient mass levels to achieve significant economies of scale. so, we are recommending the future people that plan to build this project for the same purposes to make a perfect studying for the project and choose the right location for the project. We recommend building the project in a wide area like in the western or the eastern desert Because the project needs wide scanners. The project can be established in regions where the temperature is higher, especially the desert like the coast of the red sea and the new valley area because the project is operating in the (MENA) region, especially Egypt and Morocco, where the temperature is higher than the other countries in the (MENA) region. The project can power up the whole city, and that would lead people to build the project alongside the desert towns.

\section{REFERENCES}

[1] Bouhal, T., Agrouaz, Y., Kousksou, T., Allouhi, A., El Rhafiki, T., Jamil, A., \& Bakkas, M. (2018). Technical feasibility of a sustainable Concentrated Solar Power in Morocco through an energy analysis. Renewable and Sustainable Energy Reviews, $81,1087-1095$. ISO 690

[2] Islam, M. T., Huda, N., Abdullah, A. B., \& Saidur, R. (2018). A comprehensive review of state-of-the-art concentrating solar power (CSP) technologies: Current status and research trends. Renewable and Sustainable Energy Reviews, 91, 987-1018.

[3] Patlitzianas, K. D. (2011). Solar energy in Egypt: Significant business opportunities. Renewable energy, 36(9), 2305-2311

[4] Zhang, H. L., Baeyens, J., Degrève, J., \& Cacères, G. (2013). Concentrated solar power plants: Review and design methodology. Renewable and sustainable energy reviews, 22, 466-481.

[5] Desideri, U., \& Campana, P. E. (2014). Analysis and comparison between a concentrating solar and a photovoltaic power plant. Applied energy, 113, 422-433.

[6] Geng, Q., Zhao, X., Gao, X., Yu, H., Yang, S., \& Liu, G. (2012). Optimization design of CuCrxMn2- xO4-based paint coatings used for solar selective applications. Solar energy materials and solar cells, 105, 293-301.

[7] Behar, O., Khellaf, A., \& Mohammedi, K. (2013). A review of studies on central receiver solar thermal power plants. Renewable and sustainable energy reviews, 23, 12-39.

[8] Nag, P. K. (2015). Power plant engineering. New Delhi: McGraw Hill Education (India) Private.

[9] Rajavi, Y. (2013, November 5). Concentrating Solar Power. Retrieved May 11, 2013, from http://large.stanford.edu/courses/2013/ph240/rajavi1/ 